\title{
Gastrointestinal symptoms in patients with asthma
} Carlo Caffarelli, Franca Maria Deriu, Vittorio Terzi, Francesca Perrone,
Gianluigi dè Angelis, David J Atherton

Clinica Pediatrica, Università di Parma, Via Gramsci 14, 43100 Parma, Italy

C Caffarelli

V Terzi

F Perrone

$\mathrm{G}$ dè Angelis

Dipartimento di Prevenzione, AUSL, 43100 Parma, Italy

F M Deriu

Department of Dermatology, Great Ormond Street Hospital for Children, London WC1N 3JH, UK

D J Atherton

Correspondence to: Dr Caffarelli

Accepted 12 October 1999

\begin{abstract}
Aims-Minor gastrointestinal abnormalities have been reported in children with asthma, but the prevalence of gastrointestinal symptoms in these children has not been studied.

Methods-75 children with bronchial asthma and an age and sex matched control group were recruited. Parents completed a questionnaire on gastrointestinal symptoms and on asthma. Weight and height were measured; a clinical evaluation of asthma was undertaken and skin prick tests were performed.

Results-Children with asthma had a significantly greater frequency of gastrointestinal symptoms, particularly diarrhoea, vomiting, and abdominal pain, than did controls. Gastrointestinal symptoms were slightly more common in children with atopic symptoms other than asthma, or with positive skin prick tests to foods. There was no association between current gastrointestinal symptoms and medications or attacks of asthma.

Conclusions-The occurrence of gastrointestinal symptoms appears to be common in children with asthma. These symptoms might be caused by an atopic gastroenteropathy, which might play a part in the pathogenesis of asthma in some cases.

(Arch Dis Child 2000;82:131-135)
\end{abstract}

Keywords: gastrointestinal symptoms; asthma; atopy; food challenge

in some children with atopic eczema ${ }^{9-11}$; in these children, the wheezing was also often accompanied by gastrointestinal symptoms such as abdominal pain, diarrhoea, and vomiting.

Third, it has been suggested frequently that gastro-oesophageal reflux can be a provocative factor in asthma. ${ }^{12-15}$

However, to the best of our knowledge, an association between asthma itself and gastrointestinal symptoms has not been directly sought. We demonstrated recently that a variety of gastrointestinal symptoms were significantly more frequent in children with atopic eczema than in a control population. ${ }^{16}$ Therefore, it seemed logical to ask whether a similar frequency of such symptoms could also be found in children with asthma.

\section{Material and methods}

STUDY SUBJECTS

The study group comprised 75 children aged 3-14 years with bronchial asthma, diagnosed according to standard criteria. ${ }^{17}$ The parents of all children attending Parma Hospital's paediatric outpatient clinic for asthma were invited to take part in the survey, on condition that at least one acute episode had occurred in the previous year. Recruitment took place over a four month period from the beginning of November. No parents refused to participate. The first 75 voluntary subjects were included in our study. Seventy five sex and age matched healthy children were recruited as controls, at routine annual school health examinations, with the permission of a parent. None of these control children had asthma.

There has been sporadic interest over many years in the possible relations between asthma and the gastrointestinal tract; this has been focused on three principal areas.

First, gastrointestinal abnormalities have been reported in patients with asthma. Duodenal histological changes and cytokine production of patients with asthma mimicking those observed in bronchial mucosa have been demonstrated. ${ }^{1}$ Intestinal permeability to CrEDTA also appears to be increased in asthma. ${ }^{2}$

Second, food challenge has been shown to elicit wheezing in a small proportion of children with asthma, and is frequently associated with cutaneous or gastrointestinal symptoms. ${ }^{34}$ Foods can provoke increased airway reactivity in a proportion of children with asthma. ${ }^{5}$ Food challenge has also been shown to elicit wheezing in some children presenting with gastrointestinal allergic symptoms, ${ }^{6-8}$ and

\section{METHODS}

All children were examined, and weight and height were measured.

Most of the children with asthma were receiving regularly scheduled medications. Thirty six children were receiving inhaled $\beta_{2}$ agonists, 34 inhaled corticosteroids, and 24 inhaled cromones. In the last month, 37 children received supplementary inhaled $\beta_{2}$ agonists and six oral corticosteroids. Seventeen children had not taken any drug in the last month.

Children with asthma underwent skin prick tests with commercial extracts (1/10 wt/vol; Bayropharm, Milan, Italy) of foods (hen's egg, cow's milk, goat's milk, pea, cereals, bean, peanut, banana, pear, peach, apple, cherry, soy, tomato, spinach, potato, carrot, beef, pork, lamb, chicken, cod, tuna, and salmon), and inhalant allergens (Dermatophagoides 
pteronissinus and $D$ farinae, grass pollens, mugwort, pellitory, plantain, birch, walnut, cladosporium, aspergillus, and $\mathrm{dog}$ and cat epithelium), histamine $(10 \mathrm{mg} / \mathrm{ml})$, and negative control (diluent). The test was considered positive if it elicited a weal at least $3 \mathrm{~mm}$ greater than control, ${ }^{9}$ and more than half the diameter of the weal produced with histamine.

\section{QUESTIONNAIRE}

A questionnaire was completed by the parents in the waiting room before their child's consultation. The children were present and helped to respond to the questions, as far as was appropriate for their age. Details were recorded of a history of any atopic disease in parents or siblings, and of atopic symptoms (asthma, eczema, allergic rhinitis, or conjunctivitis) in the children themselves.

The occurrence of wheeze was elicited by the question: "Has your child had difficult breathing, with a whistling sound coming from the chest, not associated with a cold, in the last 12 months?" Parents were also asked whether their child had in the past 12 months experienced: "a recurrent, annoying, dry cough, not related to a cold, especially at night or on waking?" Exercise induced asthma was elicited by the question: "Has your child ever been more breathless than you would expect, or had an annoying, dry cough during or after exercise?" Parents were also asked about seasonal occurrence of these symptoms. The frequency of symptoms was recorded as: less than once a month, less than once a week, more than once a week, very infrequent but severe attacks. Other questions about asthma included age of onset, and whether there appeared to be provocation or aggravation after the ingestion of particular foods.

There was a series of questions relating to gastrointestinal symptoms. A history of infantile colic was elicited by asking whether, in the first weeks of life, the baby "had cried for long periods (exceeding 30 minutes), especially in the evening, with flexing of limbs, perhaps associated with excessive flatulence, for which there was no apparent cause and which could not be relieved by feeding or comforting?" A history of abdominal pain was sought. The occurrence of abdominal distension was sought by asking: "Has your child's abdomen ever been swollen?" Eructation and flatulence were identified by asking whether the child had frequently expelled gas forcibly through the

Table 1 Baseline data of the study groups

\begin{tabular}{|c|c|c|c|c|}
\hline & $\begin{array}{l}\text { Asthma group } \\
(n=75)\end{array}$ & $\begin{array}{l}\text { Control group } \\
(n=75)\end{array}$ & $p$ Value & OR $(95 \% C I)$ \\
\hline Age (years) ${ }^{\star}$ & $8.5(3-14.3)$ & $8.4(3-14.3)$ & NS & \\
\hline Height $(\mathrm{cm})^{\star}$ & $130.2(93-171)$ & $132.7(99-185)$ & NS & \\
\hline Weight $(\mathrm{kg})^{\star}$ & $32(13-66.5)$ & $31.6(10.2-74)$ & NS & \\
\hline \multicolumn{5}{|l|}{ Number of patients } \\
\hline Male & 48 & 48 & NS & $1(0.51$ to 1.94$)$ \\
\hline Atopic family history & 60 & 27 & $<0.001$ & 7.11 (3.40 to 14.85$)$ \\
\hline \multicolumn{5}{|l|}{ Atopic symptoms } \\
\hline Eczema & 29 & 6 & $<0.001$ & 7.25 (2.79 to 18.83$)$ \\
\hline Rhinitis & 53 & 6 & $<0.001$ & $27.70(10.49$ to 73.16$)$ \\
\hline Conjunctivitis & 32 & 3 & $<0.001$ & $17.86(5.15$ to 61.85$)$ \\
\hline All of these & 66 & 15 & $<0.001$ & 29.33 (11.95 to 71.95$)$ \\
\hline
\end{tabular}

$\star$ Values are mean (range).

$\mathrm{CI}$, confidence interval; OR, odds ratio. mouth, or anus, respectively. A history of diarrhoea was elicited by asking parents whether their child had ever had three or more liquid or semi-liquid motions in a 24 hour period, ${ }^{18}$ which were not overtly caused by an infection (that is, accompanied by fever or diagnosed by a doctor as gastroenteritis). Constipation was identified by the question: "Has your child ever defecated less than once in any three day period?" Vomiting was defined as: "the forceful expulsion of gastric contents, which was not overtly caused by an infection (that is, accompanied by fever or diagnosed by a doctor as gastroenteritis)." Regurgitation was defined as: "the passive reappearance in the mouth, or flow out of the mouth, of food that had previously been swallowed." The presence of heartburn was sought by asking: "Has your child ever complained about pain under the breastbone?" Parents were also asked when symptoms had first appeared, and whether they had occurred after ingestion of particular foods. Symptoms were considered "current" if they had occurred during the previous month. Before the study, the questionnaire had been completed by the parents of 30 children with suspected asthma and by the parents of 30 children with suspected gastrointestinal complaints. Answers agreed with medical findings.

\section{STATISTICS}

The expected frequency of gastrointestinal symptoms in the paediatric population is about $55 \%$. We estimated that at least 55 children in each group were required to detect a $50 \%$ increase in gastrointestinal symptoms in children with asthma, with $90 \%$ power, assuming significance at the 5\% level. Age and anthropometric measurements were compared by analysis of variance. Chi squared analysis with Yates's correction or Fisher's exact test were used to compare proportions. Results were considered significant if $\mathrm{p}<0.05$. The odds ratio (OR) and $95 \%$ confidence intervals (CI) were also calculated.

\section{Results}

No parent refused to take part in the survey, and every questionnaire was fully completed.

There were 48 boys and 27 girls in both the asthma group and the control group (table 1). The mean age of the asthma group was 8.5 years and that of the control group was 8.4 years (table 1). There was no significant difference in height and weight between the asthma and the control groups (table 1), or in the asthma group between children with and without gastrointestinal symptoms (table 2). Atopic family history, atopic eczema, rhinitis, and conjunctivitis were all significantly more frequent in the asthma group compared with the control group (table 1).

Asthma had first appeared before the age of 4 years in 43 of the children, and before 8 years in 69 (mean age of onset, 3 years 6 months; range, 3 months to 11 years 1 month). Only one child had a history of asthma exacerbated by ingestion of particular foods. In 57 children, the asthma was seasonal and in 28 it had been 
Table 2 Demographic data, skin prick test results, and atopic symptoms in children with asthma grouped by presence of gastrointestinal symptoms

\begin{tabular}{|c|c|c|c|c|}
\hline & $\begin{array}{l}\text { With gastrointestinal } \\
\text { symptoms }(n=58)\end{array}$ & $\begin{array}{l}\text { Without gastrointestinal } \\
\text { symptoms }(n=17)\end{array}$ & $p$ Value & OR $(95 \% C I)$ \\
\hline \multicolumn{5}{|l|}{ Characteristics of children } \\
\hline Male/female & $36 / 22$ & $6 / 11$ & NS & $3(0.97$ to 9.26$)$ \\
\hline Mean (range) age (years) & $8.7(3-14.3)$ & $7.5(3.7-12.9)$ & NS & \\
\hline Mean (range) height $(\mathrm{cm})$ & $132.3(93-171)$ & $123.4(99-165)$ & NS & \\
\hline Mean (range) weight (kg) & $33(13-66.5)$ & $28(13.4-66)$ & NS & \\
\hline \multicolumn{5}{|l|}{ Skin prick tests } \\
\hline \multicolumn{5}{|l|}{ Number of children positive for at least } \\
\hline 1 food allergen & 26 & 1 & 0.008 & $13(1.61$ to 104.63$)$ \\
\hline \multicolumn{5}{|l|}{ Number of children positive for at least } \\
\hline $\begin{array}{l}1 \text { inhalant allergen } \\
\text { Atopic diseases }\end{array}$ & 50 & 15 & NS & $0.83(0.15$ to 4.53$)$ \\
\hline Number with atopic family history & 48 & 12 & NS & $2(0.57$ to 6.95$)$ \\
\hline \multicolumn{5}{|l|}{ Number with other atopic symptoms } \\
\hline Eczema & 25 & 4 & NS & $2.46(0.71$ to 8.46$)$ \\
\hline Rhinitis & 42 & 11 & NS & $1.43(0.45$ to 4.51$)$ \\
\hline Conjunctivitis & 24 & 1 & 0.015 & $11.29(1.40$ to 91.01$)$ \\
\hline Total with at least 1 symptom & 51 & 15 & NS & $0.83(0.15$ to 4.35$)$ \\
\hline
\end{tabular}

CI, confidence interval; OR, odds ratio.

noted to be exercise induced. The frequency of attacks was $<1 /$ month in 54 children, $<1$ /week in $13,>1 /$ week in six, and infrequent but severe in two.

Table 3 Lifetime and current prevalences of gastrointestinal symptoms in the study groups

\begin{tabular}{|c|c|c|c|c|}
\hline Symptom & $\begin{array}{l}\text { Asthma group } \\
(n=75)\end{array}$ & $\begin{array}{l}\text { Control group } \\
(n=75)\end{array}$ & p Value & OR $(95 \% C I)$ \\
\hline \multicolumn{5}{|c|}{ Any gastrointestinal symptom } \\
\hline Life & 58 & 42 & 0.009 & $2.68(1.32$ to 5.43$)$ \\
\hline Current & 28 & 9 & 0.001 & $4.36(1.88$ to 10.11$)$ \\
\hline \multicolumn{5}{|c|}{ Infantile colic } \\
\hline Life & 21 & 24 & NS & $0.82(0.41$ to 1.66$)$ \\
\hline Current & 0 & 0 & NS & - \\
\hline \multicolumn{5}{|c|}{ Abdominal pain } \\
\hline Life & 19 & 7 & 0.018 & $3.29(1.29$ to 8.40$)$ \\
\hline Current & 16 & 4 & 0.008 & $4.81(1.52$ to 15.18$)$ \\
\hline \multicolumn{5}{|l|}{ Bloating } \\
\hline Life & 9 & 4 & NS & $2.42(0.71$ to 8.23$)$ \\
\hline Current & 6 & 2 & NS & $3.17(0.62$ to 16.2$)$ \\
\hline \multicolumn{5}{|l|}{ Eructation } \\
\hline Life & 4 & 2 & NS & $2.05(0.36$ to 11.5$)$ \\
\hline Current & 3 & 0 & NS & - \\
\hline \multicolumn{5}{|l|}{ Flatulence } \\
\hline Life & 7 & 3 & NS & $2.47(0.61$ to 9.94$)$ \\
\hline Current & 5 & 2 & NS & $2.60(0.49$ to 13.88$)$ \\
\hline \multicolumn{5}{|l|}{ Diarrhoea } \\
\hline Life & 14 & 3 & 0.010 & $5.50(1.51$ to 20.06$)$ \\
\hline Current & 4 & 0 & NS & - \\
\hline \multicolumn{5}{|c|}{ Constipation } \\
\hline Life & 18 & 10 & NS & 2.05 (0.87 to 4.80$)$ \\
\hline Current & 13 & 7 & NS & $2.03(0.76$ to 5.43$)$ \\
\hline \multicolumn{5}{|l|}{ Vomiting } \\
\hline Life & 12 & 1 & 0.004 & $14.09(1.78$ to 111.42$)$ \\
\hline Current & 2 & 0 & NS & - \\
\hline \multicolumn{5}{|c|}{ Regurgitation } \\
\hline Life & 27 & 16 & 0.071 & $2.07(1.00$ to 4.28$)$ \\
\hline Current & 1 & 0 & NS & - \\
\hline
\end{tabular}

CI, confidence interval; OR, odds ratio.

Table 4 Frequency of asthma attacks and asthma medication in children with and without current gastrointestinal symptoms

\begin{tabular}{lllll}
\hline & $\begin{array}{l}\text { With current } \\
\text { GI symptoms } \\
(n=28)\end{array}$ & $\begin{array}{l}\text { Without } \\
\text { current } G I \\
\text { symptoms } \\
(n=47)\end{array}$ & p Value & OR $(95 \%$ CI $)$ \\
\hline $\begin{array}{l}\text { Frequency of asthma attacks } \\
\text { Mild asthma }\end{array}$ & 22 & 32 & NS & $1.71(0.57$ to 5.11$)$ \\
$\begin{array}{l}\text { Moderate asthma } \\
\text { Asthma medication }\end{array}$ & 6 & 15 & NS & $0.58(0.19$ to 1.73$)$ \\
Inhaled $\beta_{2}$ agonists & 15 & & & \\
$\quad$ Regularly scheduled & 16 & 21 & NS & $1.42(0.55$ to 3.65$)$ \\
$\quad$ Supplementary (as needed) & 11 & 13 & NS & $1.65(0.64$ to 4.24$)$ \\
Inhaled cromones & 14 & 20 & NS & $1.52(0.57$ to 4.07$)$ \\
Inhaled corticosteroids & 3 & 3 & NS & $1.35(0.52$ to 3.45$)$ \\
Oral corticosteroids & & 0.33 to 9.38$)$ \\
\hline
\end{tabular}

Frequency of asthma attacks: $<1 /$ month, mild asthma; $>1 /$ month or infrequent but severe, moderate asthma.

CI, confidence interval; OR, odds ratio.
GASTROINTESTINAL SYMPTOMS

Gastrointestinal symptoms were reported by parents with significantly greater frequency in the asthma group (table 3); abdominal pain, diarrhoea, and vomiting were specifically reported to be significantly more frequent. Several other gastrointestinal symptoms were also reported with increased frequency, although results were not significant; these were: abdominal distension, constipation, eructation, flatulence, and regurgitation. There was no suggestion of an increased frequency of infantile colic. The mean age of onset of the gastrointestinal symptoms in the children with asthma did not differ from the controls (mean 25.3 months, range 1-105 $v$ mean 16.7, range 1-96). Abdominal complaints preceded the onset of the asthma in 50 of 58 of the children. Gastrointestinal symptoms were no more common in the children who had more frequent attacks of asthma. The children with asthma were classified into two groups: one group with mild asthma had attacks $<1 /$ month and one group with moderate asthma had attacks > $1 /$ month or infrequent but severe attacks. There was no association among current gastrointestinal symptoms and mild asthma, moderate asthma, or medications (table 4). No association was found between the occurrence of any gastrointestinal symptom and the sex of the child, or the ingestion of particular foods. The children with asthma and gastrointestinal symptoms were slightly more likely to have concurrent eczema, but the association did not reach significance (table 2); they were no more likely to have rhinitis. Conjunctivitis was significantly more frequent in children with asthma and gastrointestinal symptoms (table $2)$. In the control group, there was no association between the presence of gastrointestinal symptoms and either a family history of atopic diseases or a personal history of other atopic manifestations.

SKIN PRICK TESTS

In the children with asthma who had gastrointestinal symptoms, positive skin prick tests to foods were more common than in those who did not have symptoms (table 2); only the 
association with diarrhoea (nine of $27 v$ five of $48 ; \mathrm{p}=0.03 ; \mathrm{OR}=4.3 ; 95 \%$ CI, 1.26 to 14.62) and vomiting (nine of $27 v$ three of 48; $\mathrm{p}=0.006 ; \mathrm{OR}=7.5 ; 95 \% \mathrm{CI}, 1.81$ to 30.91 ) were specifically reported to be significantly more frequent. Children with asthma and a positive test to foods were more likely to have a history of gastrointestinal symptoms after ingestion of a particular (not necessarily the same) food (12 of $27 v$ nine of 48; p = 0.03; $\mathrm{OR}=3.46 ; 95 \% \mathrm{CI}, 1.21$ to 9.90 ), and were more likely to have eczema ( 24 of $27 v$ five of $48 ; \mathrm{p}<0.001 ; \mathrm{OR}=68.80 ; 95 \% \mathrm{CI}, 15.10$ to 313.30).

\section{Discussion}

Our survey suggests that gastrointestinal symptoms, particularly vomiting, diarrhoea, and abdominal pain, are common in children with asthma. As far as we are aware, such a finding has not been reported previously, but is consistent with studies showing gastrointestinal abnormalities in patients with bronchial asthma. ${ }^{2}$

In our study, data on abdominal complaints were self reported, raising a question of reliability. However, several factors might have contributed to the validity of answers. All questionnaires were completed with a research assistant present to explain the instruments and answer any queries. Parents were instructed that there were no right or wrong answers. All eligible parents participated. Furthermore, it is noteworthy that data were obtained with the same procedure both in patients and controls. Therefore, we believe that no significant bias was introduced.

The reason for abdominal complaints being associated with asthma is unclear. It is possible that asthma might itself be able to induce gastrointestinal symptoms. It has been shown that transdiaphragmatic pressure is increased in patients with asthma, ${ }^{19}$ which would be likely to increase the prevalence of symptomatic gastro-oesophageal reflux. ${ }^{14}$ Although this might explain the increased frequency of regurgitation in our asthma group, it is unlikely to explain any of the other reported symptoms. Furthermore, we found no association between gastrointestinal symptoms and number of attacks of asthma. Another possibility might be that drugs used for asthma might be responsible for the development of gastrointestinal symptoms. Among these, theophylline, $\beta_{2}$ agonists, and corticosteroids might decrease lower oesophageal sphincter pressure, ${ }^{20-22}$ but there is no evidence that these drugs provoke an increase in gastro-oesophageal reflux in patients with asthma. ${ }^{13}$ Theophylline could be responsible for an increase in abdominal pain. However, our results showed no association between administration of $\beta_{2}$ agonists, cromones, or corticosteroids and current gastrointestinal symptoms. No child took theophylline. Furthermore, most of our children with asthma and gastrointestinal symptoms reported that the symptoms developed before the onset of asthma, ruling out a causative role for these treatments. We believe that the most likely explanation is that the gastrointestinal symptoms and asthma are both a consequence of the children's atopic status. This is consistent with our previous finding that similar gastrointestinal symptoms can be identified with much the same frequency in children with atopic eczema. ${ }^{16}$ We interpret our data as indicating that there might be an atopic gastroenteropathy that is common in children with eczema or asthma. The functional importance of such an atopic gastroenteropathy is unknown, and requires further study. One question that needs to be investigated is whether this could be a contributory factor to the growth delay that is sometimes seen in children with atopic eczema ${ }^{23}{ }^{24}$ and asthma. ${ }^{25}$ The type of gastrointestinal symptoms recorded in our study do not appear to be associated with overt malabsorption in most cases, but the possibility of more subtle effects on absorptive function cannot be discounted. In most cases, the main problem resulting from the gastroenteropathy appears to be a variety of unpleasant symptoms. It is probably because of the lack of serious functional consequences that these symptoms have received so little attention in the literature.

The provocation of asthma by the ingestion of particular foods is well documented, ${ }^{3-11}$ often with the simultaneous appearance of gastrointestinal symptoms. The finding in our asthma group of associations between gastrointestinal symptoms and (1) food provocation of such symptoms, and (2) positive prick tests to foods suggests a pathogenetic role for foods in the development of these gastrointestinal symptoms. In our patients, a role for food allergy can be established definitively only by controlled food challenge. However, there are two other considerations. The first is that the migration of activated lymphocytes from the bronchial mucosa lymphoid tissue might cause an inflammation of the intestinal mucosa ${ }^{1}$ as well as abdominal complaints. A second possibility is that inhalation of an allergen might be responsible for abdominal complaints.

We have identified a subgroup of children with asthma and gastrointestinal symptoms. These symptoms might be caused by an atopic gastroenteropathy. Further investigations are needed to determine whether any modification of diet would affect the prevalence or severity of both abdominal complaints and asthma.

1 Wallaert B, Desremaux P, Copin MC, et al. Immunoreactivity for interleukin 3 and 5 and granulocyte/macrophage colony-stimulating factor of intestinal mucosa in bronchial colony-stimulating factor of intestinal muco

2 Benard A, Desremaux P, Huglo D, Hoorelbeke A, Tonnel Benard A, Desremaux P, Huglo D, Hoorelbeke A, Tonnel
$\mathrm{AB}$, Wallaert B. Increased intestinal permeability in AB, Wallaert B. Increased intestinal permeability in bronchial asthma. F Allergy Clin Immunol 1996;97:1173-8.
Novembre E, de Martino M, Vierucci A. Foods and respiratory allergy. F Allergy Clin Immunol 1988;81:1059-65.

4 Onorato J, Merland N, Terral C, Michel FB, Bousquet J. Placebo-controlled double-blind food challenge in asthma. f Allergy Clin Immunol 1987;78:1139-46.

5 James JM, Eigenmann PA, Eggleston PA, Sampson HA. Airway reactivity changes in asthmatic patients undergoing
blinded food challenge. Am $\mathcal{F}$ Respir Crit Care Med 1996;153:597-603.

6 Boch SA, Atkins FM. Patterns of food hypersensitivity during sixteen years of double-blind, placebo-controlled food challenges. $¥$ Pediatr 1990;117:561-7.

7 Jakobsson I, Lindberg T. A prospective study of cow's milk protein intolerance in Swedish infants. Acta Paediatr Scand 1979;69:853-9.

8 Hill DJ, Firer MA, Shelton MJ, Hosking CS. Manifestations of milk allergy in infancy: clinical and immunologic findings. $\mathcal{F}$ Pediatr 1986;109:270-76. 
9 Sampson HA, Albergo R. Comparison of results of skin tests, RAST, and double-blind, placebo-controlled food
challenges in children with atopic dermatitis. $\mathcal{F}$ Allergy Clin challenges in children with
Immunol 1984;74:26-33.

10 Sampson HA, McCaskill CC. Food hypersensitivity and atopic dermatitis: evaluation of 113 patients. I Pediatr 1985;107:669-75.

11 Burks WA, Mallory SB, Williams LW, Shirrel MA. Atopic dermatitis: clinical relevance of food hypersensitivity reactions. F Pediatr 1988;113:447-51.

12 Anonymous. Reflux and respiratory symptoms. Lancet 1990;336:282-3.

13 Sontag SJ, O'Connell S, Khandelwal S, et al. Most asthmatics have gastroesophageal reflux with or without bronchodilator therapy. Gastroenterology 1990;99:613-20.

14 Boyle JT, Tuchman DW, Altschuler SM, Nixon TE, Pack AI, Cohen S. Mechanism for the association of gastro1985:131(suppl):S16-20.

15 Gustafsson PM, Kjellman NIM, Tibbling L. Bronchial asthma and acid reflux into the distal and proximal asthma and acid reflux into the distal
oesophagus. Arch Dis Child 1990;65:1255-8.

16 Caffarelli C, Cavagni G, Deriu FM, Zanotti P, Atherton DJ. Gastrointestinal symptoms in children with atopic eczema. Arch Dis Child 1998;78:230-4.
17 Asthma: a follow up statement from an international paediatric asthma consensus group. Arch Dis Child 1992;67:240-8.

8 Baqui $\mathrm{AH}$, Black RE, Yunus MD, Hoque AR, Chowdury HR, Sack RB. Methodological issues in diarrhoeal diseases epidemiology: definition of diarrhoeal episodes. Int $\mathcal{F}$ Epidemiol 1991;20:1057-63.

19 Stalcup SA, Mellins RB. Mechanical forces producing pulmonary edema in acute asthma. $N$ Engl $\mathcal{F}$ Med 1977;297:592-6.

20 Stein MR, Towner TG, Weber RW, et al. The effect of theophylline on the lower esophageal sphincter pressure. Ann Allergy 1980;45:238-9.

21 Shapiro GG, Christie DL. Gastroesophageal reflux in steroid dependent youths. Pediatrics 1979;63:207-12.

22 DiMarino AJ, Cohen S. Effect of an oral beta 2-adrenergic agonist on lower esophageal sphincter pressure in normals and in patients with acalasia. Dig Dis Sci 1982;27:1063-6.

23 Pike MG, Chang CL, Atherton DJ, Carpenter RG, Preece MA. Growth in atopic eczema: a controlled study by quesMA. Growth in atopic eczema: a controle

24 Patel L, Clayton PE, Jenney MEM, Ferguson JE, David TJ. Adult height in patients with childhood onset atopic dermatitis. Arch Dis Child 1997;76:505-8.

25 Balfour-Lynn L. Growth and childhood asthma. Arch Dis Child 1986;61:1049-55. 